\title{
DISCUTINDO 0 GERENCIAMENTO PARA A MUDANÇA: 0 FRAMEWORK 5M
}

\author{
Discussing management to change: the 5M framework
}

Vera L. Cançado*

Richard Badham**

\section{RESUMO}

Este artigo tem como objetivo discutir e apresentar a sustentação teórica do framework $5 \mathrm{M}$, desenvolvido com o intuito de conduzir gestores de uma visão acrítica e racional do gerenciamento da mudança para uma leitura mais crítica e pragmática, focada no gerenciamento para a mudança. Adotou-se a abordagem da mudança como drama, combinando o que vem sendo comumente descrito como uma visão fraca das organizações "como se fossem drama" e a visão forte das organizações "como drama de fato". 0 exemplo da aplicação do framework $5 \mathrm{M}$ em um Master of Business Administration (MBA) de Gestão permitiu avaliar o seu impacto como veículo retórico de educação e prática de gerenciamento, bem como fornecer sugestão para posteriores refinamentos teórico-pedagógicos.

Palavras-chave: Mudança organizacional. Gerenciamento para a mudança. Abordagem da mudança como drama.

\begin{abstract}
This paper aims to discuss and present the theoretical support of the $5 \mathrm{M}$ framework, developed to guide managers from an uncritical and rational view of management of change to a more critical and pragmatic focus on managing to change. By adopting the change as drama approach, we combined what is commonly described as a weak view of organizations-as-drama and the strong view of organizations like drama. The example of the application of the 5M framework in an MBA course allowed to evaluate its impact as a rhetorical vehicle of education and management practice, as well as to provide suggestions for later theoretical-pedagogical refinements.
\end{abstract}

Keywords: Organizational change. Managing to change. Change as drama approach.

\footnotetext{
* Doutora em Administração pelo Centro de Pós-Graduação e Pesquisas em Administração da Universidade Federal de Minas Gerais (UFMG). Professora Titular do Mestrado Profissional em Administração pela Fundação Pedro Leopoldo - Belo Horizonte (MG), Brasil. E-mail: vera.cancado@fpl.edu.br. ORCID: 0000-0003-48740553

** Ph.D in Sociology of the University Warxick and University of Leeds. Professor of Management, Macquarie Graduate School of Management for Macquaire University - Sidney, Australia. E-mail: richard.badham@mgsm. edu.au. ORCID: 0000-0003-4755-4775
} 


\section{INTRODUÇÃO: A RETÓRICA DO GERENCIAMENTO DA MUDANÇA}

$\mathrm{N}$ as últimas décadas começaram a ser difundidos, e ganharam crescente reconhecimento, estudos sobre mudança organizacional fundamentados nas abordagens processual, sensemaking ${ }^{1}$ e visão baseada na prática (Practice Based Review) (BEER; NOHRIA, 2000; BROWN; EISENHARDT, 1998; COLLINS, 1998; STACEY, 2012; WEICK, 2001). Esses estudos contrapõem-se ao entendimento da mudança como um processo linear, planejado e em n-etapas, reconhecem a natureza caótica e emergente da prática da mudança nas organizações, como destacado por Badham, Mead e Antacopalou (2012), Collins (1998), Jabri (2012) e Weick e Quinn (1999). Assim, segundo Badham (2013), desloca-se a concepção do gerenciamento da mudança como um processo de controle, para o gerenciamento para a mudança, entendido como uma jornada complexa, caótica e paradoxal.

Apesar do surgimento e difusão dessas ideias nos estudos organizacionais, ainda não se vê, de fato, o seu impacto na educação e na prática gerencial, devido, principalmente, a dois fatores. Primeiro, de acordo com Buchanan e Boddy (1992), os seus defensores, ao não advogarem o controle ou checklists, não propõem ou não produzem um conhecimento funcional. Em segundo lugar, as retóricas e os rituais dominantes nas organizações modernas mantêm o seu caráter racional. Conforme March (1994, p. 216) observou:

Em uma sociedade baseada na razão, na racionalidade e na concepção do controle humano intencional sobre nosso destino, o processo decisório torna-se uma atividade sagrada. Imagina-se o mundo produzido por ações humanas deliberadas e atentas às intenções humanas [ [...]] e as escolhas como sendo guiadas pela ação. Tais tradições do racionalismo e antropocentrismo encontram manifestações míticas e ritualísticas na ideia da tomada de decisões. Como resultado, o processo de fazer uma escolha no contexto atual é tão cercado de simbolismo e de parafernália ritualística como a vontade divina de Deus na Idade Média (tradução dos autores).

Tais fatores inibem uma crítica às visões racionais da mudança. Discussões e considerações formais sobre a natureza confusa, política e, por vezes, ineficiente da mudança permanecem inquestionáveis, como um "elefante no quarto" - usando-se a metáfora de Zerubavel (2006) sobre o silêncio e a negação. Ainda, como marcantemente afirmou Argyris (2010), o fato de não haver uma discussão sobre o tema, ao menos nos fóruns oficiais e públicos, torna-o inquestionável em si mesmo!

Para ajudar a tratar desse fenômeno, foi desenhado o framework 5M como um veículo retórico. No tocante à teoria acadêmica, esse framework foi elaborado para capturar e integrar o que é comumente chamado de abordagem organizacional dramatúrgica (BADHAM; MEAD; ANTONACOPOULOU, 2012). Como um recurso educacional, o framework também foi estruturado de forma a apoiar estudos organizacionais acadêmicos e educar gestores para o gerenciamento para a mudança.

1. Termo sem tradução no português. O sensemaking é compreendido como um processo de construção de sentidos plausíveis para as experiências e situações vivenciadas pelas pessoas (WEICH, 2001). 
Metodologicamente, a discussão apresentada neste artigo apoiou-se em três principais percursos. Primeiro, ao incorporar e integrar as abordagens processuais, sensemaking e visão baseada na prática, a intenção é deslocar a discussão do gerenciamento da mudança de um ponto de vista acrítico e racional para o gerenciamento para a mudança, a partir de uma visão mais crítica e pragmática.

Segundo, são incorporadas as visões "forte" e "fraca" sobre as organizações, a partir da dramaturgia de Goffman (1959) - de organizações vistas como se fossem drama - e do dramatismo de Burke (1969) - de organizações vistas como drama de forma literal. De um lado, a dramaturgia de Goffman fornece uma introdução para o gerenciamento da impressão, exigido pelo próprio gerenciamento e pela liderança da mudança. De outro, o dramatismo de Burke é empregado para ampliar tal visão, fornecendo perspectivas das dimensões da mudança como drama, de natureza inerentemente performática.

Em terceiro lugar, o framework combina as duas visões, revelando o papel central das retóricas formais e dos rituais de racionalidade nas organizações modernas. Para tal, baseia-se no gerenciamento para a mudança, tanto em termos do "frontstage" (palco), daquilo que é público, racional, relativo às performances oficiais, quanto das atividades de "backstage" (bastidores), referentes à política e às emoções inerentes aos programas de mudança (BUCHANAN; BODDY, 1992; BURNS, 1961).

Ao deslocar a retórica do gerenciamento da mudança para a do gerenciamento para a mudança, a significativa contribuição deste trabalho é explorar e discutir o framework $5 \mathrm{M}$, combinando a linguagem de consultoria organizacional com o contraditório e imaginário da cultura da racionalidade, evidenciado por meio do anagrama: mobilizar, manter-se atento, mapear, usar máscaras e mirar².

A adoção dessa abordagem sobre a mudança organizacional é nova e sugestiva e, apesar de Badham, Mead e Antonacopoulous (2012) terem debatido a questão, eles não forneceram um quadro de referência para explorar o gerenciamento para a mudança. Badham, Cançado e Darief (2015) discutiram os antecedentes e a aplicação do framework $5 \mathrm{M}$, mas não aprofundaram na sustentação teórica do modelo. Dessa forma, a proposição deste artigo contribui ao trazer robusta discussão e suprir essa lacuna.

Assim, o objetivo deste artigo é delinear a estrutura teórica e conceitual do framework $5 \mathrm{M}$, a maneira como seus diferentes elementos combinam para atingir o efeito retórico e trazer uma reflexão sobre como ele pode ser aplicado e avaliado.

Esta discussão teórica está organizada em quatro seções, além desta introdução. Na primeira seção, aborda-se o gerenciamento para a mudança, por meio da visão "Iimitada" e "densa", trazendo uma discussão baseada na revisão de literatura referente às abordagens processual, sensemaking e na visão baseada na prática. Na segunda, discute-se o framework 5M, incorporando as visões fortes e fracas da abordagem do drama no gerenciamento para a mudança, a partir da dramaturgia em Goffman (1959) e do dramatismo de Burke (1969). Na terceira seção, a título de ilustração, demonstra-se a aplicabilidade do framework 5M, seguindo-se, na quarta, as considerações finais.

2. Visando manter o anagrama: em inglês Mindful, Mobile, Maps, Masks and Mirrors; traduzido para o português Mobilizar, Manter-se atento, Mapear, usar Máscaras e Mirar. 


\section{GERENCIAMENTO PARA A MUDANÇA: DE UMA VISÃO “LIMITADA" PARA A “DENSA"}

Estudos tradicionais e convencionais sobre mudança discutem a performance pública da vida organizacional (frontstage ou palco), que reflete a legitimação legal-racional, o controle e a dominação burocrática (BURNS, 1961; WEBER, 1997). Essa perspectiva, denominada limitada, considera processos de mudança em termos restritos e racionais, como sendo intervenções planejadas, com objetivos estratégicos definidos, que visam aprimorar a saúde da organização, como apresentado pela clássica abordagem do desenvolvimento organizacional (BECKHARD, 1969; BENNIS, 1969; LAWRENCE; LORSCH, 1967; SCHEIN, 1969, WALTON, 1969) e pelos modelos de $n$-etapas sequenciais e planejadas para gerenciar as mudanças (COLLINS, 1998; LEWIN, 1964).

Como é amplamente reconhecido pela literatura tradicional (e mesmo na crítica), mais de $70 \%$ dos processos de mudança organizacional são considerados fracassos, como atestam Isern, Meaney e Wilson (2009) e Keller e Aiken (2009). O framework 5M dramatiza essa falha, apresentando sua primeira imagem retórica: a figura da "roleta russa" - uma arma carregada, com a legenda "[...] você tem 2,5 chances a mais de sobreviver à roleta russa do que a um programa de mudança!" (Figura 1 ).

\section{Roleta russa}

\section{Você tem 2,5 chances a mais de sobreviver à roleta russa do que a um programa de mudança}

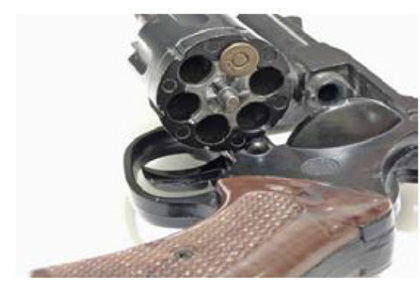

Figura 1 - Roleta Russa

Fonte: Badham (2014).

ndo além, o framework 5M, em uma visão densa, busca fornecer o tipo de análise cultural recomendada por Geertz (1983). Em sua explicação acerca da descrição limitada e densa, Geertz (1983) baseia-se no exemplo ilustrativo de Ryle (1968), que apresenta a diferença entre uma piscadela e um piscar de olhos ${ }^{3}$. Uma descrição limitada captura meramente um piscar de olhos unidimensional, entendido somente como uma contração física. Por outro lado, uma descrição densa explora o significado de uma piscadela como uma forma de comunicação multidimensional, que pode ser um conluio ou uma caricatura ou qualquer outro tipo de interação significativa.

Adaptando esse contraste para a discussão sobre racionalidade em geral e, em particular, para o gerenciamento da mudança, a abordagem tradicional, o mainstream em teoria da mudança, sugere uma visão organizacional limitada, factual e focada em descrições sem

3. Em inglês: wink e blink, respectivamente. 
interpretação. Essa visão limitada compara-se à reação motora reflexa para as informações objetivas e para as regras de decisão. A racionalidade é vista como técnica aplicada, um modo de empregar regras lógicas, coletando e avaliando evidências, tomando decisões com base nessas regras e dados, e assim por diante. Em contrapartida, uma visão organizacional densa explicita não só o comportamento, mas abrange os detalhes, as estruturas conceituais e os significados. Nesse sentido, o framework $5 \mathrm{M}$ fornece uma visão densa das práticas do gerenciamento para a mudança (BADHAM; MEAD; ANTONACOPOULOU, 2012). Traz à tona a "irracionalidade previsível" do indivíduo e do processo de decisão organizacional (ARIELY, 2008; MARCH, 1981), a ambiguidade e o caos do comportamento individual e organizacional (STACEY, 2012; WEICK, 2001) e a natureza tácita, confusa e emergente da mudança na prática (PFEFFER, 1994; WEICK; QUINN, 1999).

Nessa linha, o framework $5 \mathrm{M}$ utiliza outras duas imagens retóricas que ilustram a visão densa do gerenciamento para a mudança. A primeira é o iceberg organizacional; e a segunda, o vale da morte da mudança. 0 iceberg, popular em textos de comportamento organizacional e em literatura sobre consultoria, simboliza grande parte da vida organizacional formal, comparada à porção do iceberg submersa na água. Essa parte submersa refere-se aos aspectos informais, frequentemente tácitos e, muitas vezes, relativos ao mundo das emoções e costumes. Tais aspectos, encontrados abaixo da superfície das estruturas, sistemas e processos formais, permanecem inquestionáveis nas organizações. Essa metáfora é realçada de três maneiras: a) pela conexão das falhas dos processos de mudança à arrogância do tipo "Titanic"; b) invertendo o iceberg de forma que a substancial massa submersa seja colocada no topo, tornando-se o foco das atenções; c) e levantando a natureza inquestionável dos bastidores organizacionais - backstage -, que contradiz ou até mesmo pode minar as performances no palco organizacional - frontstage (BUCHANAN; BODDY, 1992).

A segunda imagem retórica é o clássico modelo de mudança em três etapas descongelamento, movimento e recongelamento (LEWIN, 1964), mas aqui associado à metáfora do vale da morte. Utiliza-se a imagem da montanha russa para enfatizar a dificuldade de se estimular o descongelamento, seguido do trauma e da complexidade de mover-se quando se está nas profundezas do vale da morte e, por fim, estabelecer um recongelamento sustentável que permita sair do vale da morte e que possa prevenir a volta ao mesmo. Em seguida, é mostrada a presença universal dessa imagem das três etapas em um ritual de transição abrangente. Por último, foca-se a origem dessa visão de três etapas, em reação ao caos social criado pela visão racional e suas variações gerenciais contemporâneas do estilo Just Do It Nike. Essa perspectiva é complexa para ser explicada em poucas palavras, mas envolve a crítica à visão do conhecimento como técnica aplicada, bem como de se ver a mudança como uma implementação planejada de objetivos estratégicos, enxergando a transição como um movimento simples de um estado histórico desordenado e irracional para um novo estado dinâmico e racional (BADHAM, 2013).

A partir de tais metáforas, o framework $5 \mathrm{M}$ representa uma contraimagem com 0 objetivo de fornecer uma visão densa do gerenciamento para a mudança. Esse framework foi desenvolvido com certa hesitação e receio, sendo diametralmente oposto à criação irrefletida das ferramentas de consultoria e de ensino. Ao contrário, constitui um apoio à reflexão crítica e seu intuito é apresentar a criação de conceitos e estruturas que funcionem como ponte e integrem conhecimentos de várias perspectivas para orientação e aprendizagem 
reflexiva (BADHAM, 2013). Como ilustrado na Figura 2, o framework 5M caracteriza essa abordagem como uma visão da inteligência, da ação e da jornada da mudança:

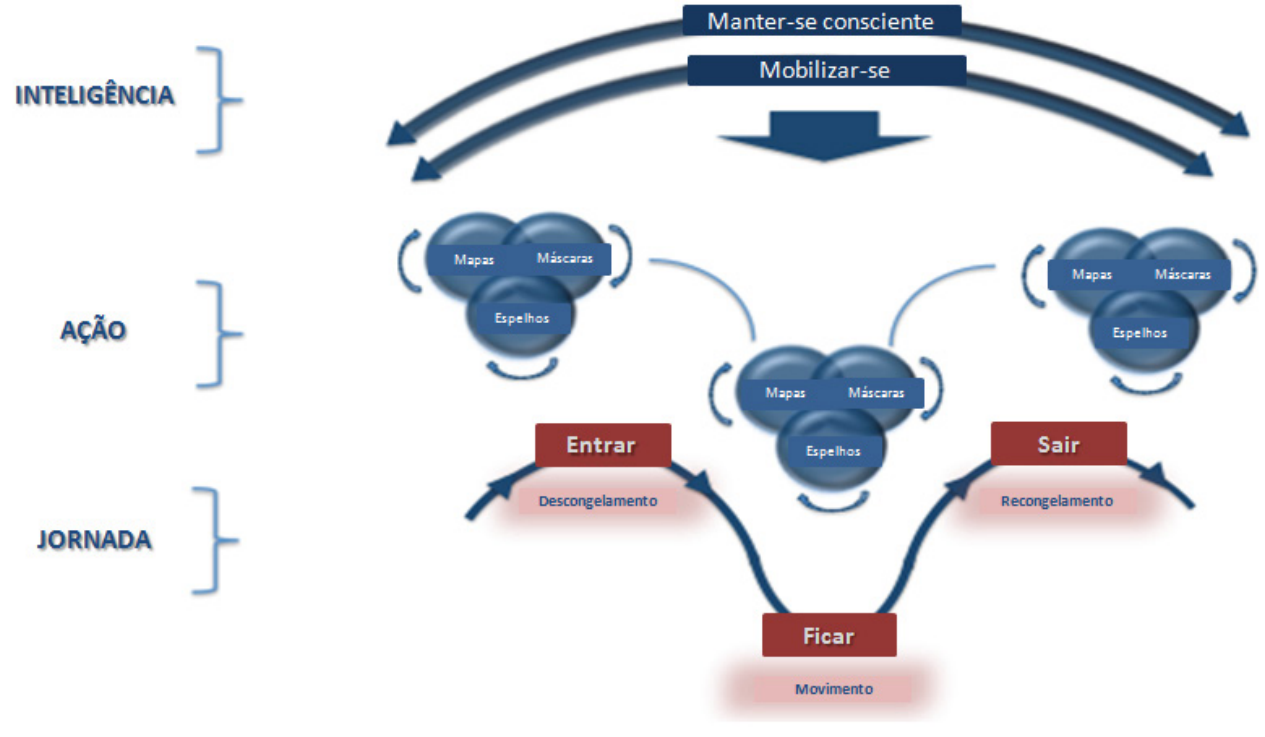

Figura 2 - Framework 5M.

Fonte: Badham (2014).

O gerenciamento para a mudança refere-se a desenvolver a inteligência da mudança em condições de incerteza e conflito, aos ciclos de ação e à efetivação da jornada, nos três estágios: descongelamento, movimento e recongelamento (BUCHANAN; BADHAM, 2008; STACEY, 2012; WEICK; SUTCLIFFE, 2001). A inteligência refere-se a manter-se atento, consciente, tendo cuidado com as lacunas, barreiras e com a complexidade envolvida na mudança. Refere-se também a mobilizar, a adquirir e distribuir proativamente recursos de forma a superar tais lacunas. Parte-se, então, para tomar as ações requeridas para mudança, por meio do mapear (criar e desenvolver mapas ou diretrizes para a jornada de mudança); usar máscaras (exercitar influência por meio de performances sociais efetivas); e mirar ou usar espelhos (estabelecer e usar reflexões efetivas e espaços de aprendizado). Essa jornada da mudança - entrar, permanecer e sair - é comparada às subidas e descidas da montanha russa (BADHAM, 2013).

O manter-se atento ou estar consciente implica aceitar que o mundo organizacional não é tão racional e previsível, como preconizado pela abordagem tradicional. É ser cauteloso e consciente sobre a existência de lacunas entre a estratégia e a implementação, entre as regras prescritas e as situações praticadas, entre a teoria e a prática (BADHAM, 2006). Tomar cuidado com as lacunas exige esperar o inesperado, estar atento e tratar os problemas antes que eles fujam do controle (HEATH; HEATH, 2010; WEICK; SUTCLIFFE, 2001). Estar consciente sobre as barreiras para a mudança envolve reconhecer as forças que a dificultam e o trabalho que gera reduzi-las; envolve atenção às barreiras pessoais e sociais à mudança (LEWIN, 1964). Cultivar uma mentalidade que reconheça a existência 
de tais barreiras refere-se a superar a tendência que organizações têm a negligenciar ou reprimir o papel das emoções, da política e de compromissos antagônicos (KEGAN; LAYEY, 2009). Estar consciente da complexidade significa ainda encorajar uma consciência coletiva que seja mais aberta, atenta e vigilante, para identificar fontes de imprevisibilidade e para lidar com emergências (LANGER, 1990; WEICK; SUTCLIFFE, 2001). Essas várias formas de consciência requerem disciplina, treino e experiência nas áreas do pensamento lógico, dos sentimentos e da ação.

O gerenciamento para a mudança também exige a mobilização proativa de pessoas e de recursos, de forma a assegurar energia e apoio para empreender a mudança. Para tanto, é necessário adotar uma mentalidade empreendedora, vencer a burocracia para que as coisas possam acontecer e, ao mesmo tempo, questionar e quebrar estruturas preestabelecidas (BRUCH; VOGEL, 2011; COVEY, 2005, 2009; KANTER, 1983; KOTTER, 2012; WEISBORD, 2011). É importante a criação de coalisões que mantenham e sustentem a energia, os recursos e a inteligência necessários para superar a inércia e a resistência, bem como a administração de conflitos de interesses, buscando uma solução ganha-ganha, vantajosa para ambos os lados (BUCHANAN; BADHAM, 2008). Desse modo, é possível abordar de maneira efetiva emoções e interesses, bem como as resistências existentes nas subidas e descidas da montanha-russa da mudança.

No tocante à ação, mapear a mudança é indispensável para se obter orientação e criar confiança e apoio. Apesar da mudança ser emergente, caótica e imprevisível, o mapeamento é necessário. 0 termo mapear é empregado deliberadamente como sendo algo mais flexível que planejar; mapear reconhece que o mapa não é o território, mas somente uma ferramenta artificial, usada por aquele que o lê (WEICK, 2001). Aquilo que é mapeado é, com frequência, incerto e ambíguo, em função de premissas implícitas, emoções flutuantes e políticas ocultas, abaixo do topo do iceberg. As ferramentas para o mapeamento são as tradicionalmente utilizadas, pela visão limitada, como, por exemplo, análise de gaps, análise do campo de força, identificação dos estágios de mudança etc (BRIDGES; BRIDGES, 2009; GALLOS, 2006; KOTTER, 2012; LEWIN, 1964; PALMER; DUNFORD; AKIN, 2008). Mapear envolve o uso dessas ferramentas, mas os dados coletados e o processo de uso são reconhecidos como uma prática social complexa e desafiadora (JABRI, 2012; WEICK, 2001).

Uma coisa é mapear a mudança, outra é colocar esse mapeamento em prática, o que é realizado por meio do exercício da influência, do usar máscaras, de forma a criar performances sociais efetivas para conduzir a mudança. Em situações complexas e incertas, é necessário desempenhar múltiplos papéis, interpretar diferentes personagens e, efetivamente, colocar e tirar máscaras, sendo convincente nas interpretações. Uma vez que a autencididade e a credibilidade são componentes-chave de uma liderança eficaz (ALEXANDER, 2004; 2012), a habilidade de adotar múltiplas máscaras e de ser percebido como autêntico e confiável é um requisito crucial para liderar a mudança de maneira efetiva. Um recurso-chave é saber lidar com interesses e perspectivas contraditórios, bem como com as questões paradoxais inerentes à mudança. Isso vai além da cognição ou até mesmo da conscientização emocional, ao incluir a complexidade social e comportamental exigida para lidar com papéis variados, tirando e colocando grande variedade de máscaras (BROWN; EISENHARDT, 1998; BURKE, 1969; GOFFMAN, 1959). Para lidar com os paradoxos da mudança são necessárias habilidades também paradoxais de planejar e improvisar, gerir e 
liderar e, ainda, ser tanto coercitivo como participativo (BUCHANAN; BADHAM, 2008). Envolve também a habilidade de pesquisar e adotar novas técnicas e ferramentas úteis (BEER; NOHRIA, 2000; FUDA, 2013; KOTTER, 2012), sendo capaz de interpretar, adaptar e implantá-las em contextos particulares, muitas vezes, conflituosos (GRINT, 2001; HUCZYNSKI, 2004).

Como elemento final, é importante a habilidade de mirar ou usar espelhos, fornecendo fontes múltiplas de reflexão, avaliação e feedback. Mirar significa olhar para o futuro, tendo como referência o passado. Para tanto, é necessário coletar e refletir sobre o conhecimento, a expertise e o saber fazer - know how (ARGYRIS, 1990, 2010; RYLE, 2000; SCHÖN, 1983). É necessário também ter um conhecimento que é, em geral, implícito, baseado na intuição e fundado em experiências complexas e específicas (NONAKA; TAKEUCHI, 1995). Essas múltiplas dimensões incorporam pensamento, emoção e ação, estimulando a inteligência tanto emocional como intelectual, bem como a sabedoria prática (COVEY, 2005, 2009; GOLEMAN, 1995; KOTTER, 2012). Finalmente, a criação de espelhos apropriados que permitam a reflexão e avaliação da jornada da mudança em curso implica estabelecer ambientes abertos ao conhecimento, com a criação de espaços de aprendizagem (ARGYRIS, 2010; SENGE et al., 1999; SENSE, 2008), bem como tempo e apoio político necessários à reflexão (BUCHANAN; BADHAM, 2008).

Sintetizando, apresenta-se o Quadro 1, com o aprofundamento e sustentação teórica propostos nesta revisão, complementando Badham, Mead e Anacopoulou (2012) e Badham, Cançado e Darief (2015). O framework 5M, na visão densa, integra os elementos com a mobilização consciente de mapas, máscaras e espelhos, contrapondo-se à visão tradicional do gerenciamento da mudança, como aplicação de técnicas e concepção de papéis no planejamento, execução e avaliação da mudança.

Quadro 1 - Framework 5M: visão limitada e densa

\begin{tabular}{|c|l|l|}
\hline \multirow{4}{*}{} & \multicolumn{1}{|c|}{$\begin{array}{c}\text { Visão limitada } \\
\text { (Desenvolvimento Organizacional (DO) }\end{array}$} & \multicolumn{1}{c|}{ Visão densa 5M } \\
\hline \multirow{4}{*}{$\begin{array}{c}\text { Agência da } \\
\text { mudança }\end{array}$} & $\begin{array}{c}\text {-Uso de ferramentas e técnicas eficazes } \\
\text { => kit de ferramentas }\end{array}$ & - Racionalidade x imprevistos \\
\cline { 2 - 4 } & - Regras lógicas & - Agir consciente \\
\cline { 2 - 4 } & - Especialista em DO & $\begin{array}{l}\text { - Cuidado com as lacunas, barreiras e } \\
\text { complexidade }\end{array}$ \\
\cline { 2 - 4 } & & $\begin{array}{l}\text { - Reconhecer o papel das emoções, da } \\
\text { política e de compromissos concorrentes }\end{array}$ \\
\hline \multirow{4}{*}{$\begin{array}{c}\text { Papéis da } \\
\text { mudança }\end{array}$} & Papéis desenhados & \multicolumn{1}{c|}{ Mobilizar } \\
\cline { 2 - 4 } & - Foco na estrutura & $\begin{array}{l}\text { - Mobilizar pessoas e recursos de forma } \\
\text { proativa }\end{array}$ \\
\cline { 2 - 4 } & & $\begin{array}{l}\text { - Lidar com burocracias; desfazer estruturas } \\
\text { - mentalidade empreendedora }\end{array}$ \\
\cline { 2 - 4 } & & - Criar coalisões \\
\cline { 2 - 4 } & & - Superar inércias e resistências \\
\hline
\end{tabular}




\begin{tabular}{|c|c|c|}
\hline & $\begin{array}{c}\text { Visão limitada } \\
\text { (Desenvolvimento Organizacional (DO) }\end{array}$ & Visão densa $5 \mathrm{M}$ \\
\hline \multirow{4}{*}{$\begin{array}{c}\text { Planejamentoda } \\
\text { mudança }\end{array}$} & Planejamento & Mapear \\
\hline & - Coletar e avaliar evidências & $\begin{array}{l}\text { - Mapear características, padrões e dinâmi- } \\
\text { cas da jornada com flexibilidade }\end{array}$ \\
\hline & $\begin{array}{l}\text { - Definir objetivos e maneiras de alcançá- } \\
\text {-los }\end{array}$ & - Dar espaço ao incerto e à ambiguidade \\
\hline & $\begin{array}{l}\text { - Identificar a sequência de etapas plane- } \\
\text { jadas }\end{array}$ & $\begin{array}{l}\text { - Usar ferramentas diagnósticas: campos de } \\
\text { força, análises de gaps como norteadores = } \\
\text { prática social complexa }\end{array}$ \\
\hline \multirow{5}{*}{$\begin{array}{l}\text { Liderando a } \\
\text { mudança }\end{array}$} & Executar tarefas & Usar máscaras \\
\hline & $\begin{array}{l}\text { - Executar tarefas planejadas a partir de } \\
\text { objetivos definidos }\end{array}$ & $\begin{array}{l}\text { - Influenciar pessoas por meio de perfor- } \\
\text { mance }\end{array}$ \\
\hline & $\begin{array}{l}\text { - Tomar decisões com base em regras e } \\
\text { dados }\end{array}$ & $\begin{array}{l}\text { - Lidar com diferentes interesses e com os } \\
\text { paradoxos }\end{array}$ \\
\hline & & $\begin{array}{l}\text { - Adotar múltiplas máscaras - papéis } \\
\text { coerentes com as demandas, com autentici- } \\
\text { dade e credibilidade }\end{array}$ \\
\hline & & $\begin{array}{l}\text { - Planejar e improvisar; gerir e liderar; ser } \\
\text { coercitivo e participativo }\end{array}$ \\
\hline \multirow{5}{*}{$\begin{array}{c}\text { Aprendendo com } \\
\text { a mudança }\end{array}$} & Avaliar resultados & Mirar \\
\hline & - Monitorar planos & $\begin{array}{l}\text { - Olhar em espelhos: olhar para futuro, } \\
\text { tendo como referência o passado }\end{array}$ \\
\hline & - Ações planejadas $\mathrm{x}$ realizadas $\mathrm{x}$ resultados & - Refletir, avaliar e proporcionar feedback \\
\hline & - Propor ações corretivas & $\begin{array}{l}\text { - Incorporar múltiplas dimensões - inteli- } \\
\text { gência intelectual, emocional e sabedoria } \\
\text { prática }\end{array}$ \\
\hline & & - Criar espaço de aprendizagem \\
\hline
\end{tabular}

Fonte: Elaborado pelos autores, complementando Badham, Mead e Antonacopoulous (2012) e Badham, Cançado e Darief (2015).

Em cada uma dessas áreas, a visão limitada do gerenciamento da mudança como um processo racional - a partir de técnicas aplicadas, alocação de papéis e responsabilidades formais, planejamento e execução da mudança e avaliação dos resultados -- é substituída pela visão densa do gerenciamento para a mudança. O gerenciamento para a mudança envolve estar consciente da complexidade e das barreiras, mobilizar energia e apoio, mapear a jornada, colocar e retirar máscaras, com performances competentes e efetivas, e criar e utilizar espelhos, visando a espaços de aprendizagem e de reflexão.

\section{DISCUTINDO A ABORDAGEM DO DRAMA PARA O GERENCIAMENTO PARA A MUDANÇA: O FRAMEWORK 5M NAS VISÕES FRACAS E FORTES}

A abordagem do drama no gerenciamento para a mudança fornece uma valiosa contraposição àquela racional e limitada do gerenciamento da mudança. Focar a mudança como drama fornece insights relacionados tanto à liderança quanto ao gerenciamento da 
impressão, componentes-chave para o gerenciamento para a mudança. Com isso, é possível enxergar a dinâmica da mudança como encontros situacionais, bem como entender como esses encontros são na prática e como devem ser tratados. A abordagem $5 \mathrm{M}$ da mudança como drama une o que vem sendo comumente descrito como uma visão fraca das organizações "como se fossem drama" (GOFFMAN, 1959) e a visão forte das organizações "como drama de fato" (BURKE, 1969).

Essa perspectiva de análise, considerando a visão fraca e forte do gerenciamento para mudança, ancora-se nos estudos sobre a sociologia da cultura de Alexander e Smith (2004). A cultura, vista como uma variável fraca e ambivalente, é "[...] limitada por um código restrito que reflete as inibições e habitus da tradição, institucionalmente orientada para as ciências sociais". Em contraste, inspirado em Bloor (1976) e Latour e Woolgar (1986), o programa forte oferece um código teórico elaborado, no qual a "[...] ciência é entendida como uma representação coletiva, um jogo de linguagem que reflete um padrão prévio de atividade de sentido" (ALEXANDER; SMITH, 2004, p. 17). Adotando essa concepção para o gerenciamento para a mudança, a metáfora da mudança como se fosse drama (GOFFMAN, 1959) é considerada uma visão fraca, enquanto a mudança como drama (BURKE, 1969) é entendida como uma visão forte.

A comparação entre a análise da interação humana em Goffman e Burke vai além do rótulo, podendo ser classificada como abordagem dramatúrgica e dramática, respectivamente (GUSFIELD, 1989). A diferença fundamental entre ambas está na ênfase que Goffman dá ao gerenciamento da impressão, à cenografia e à arte da ilusão, capturando a superfície estratégica da vida organizacional. As performances de frontstage e backstage (palco e bastidores) são usadas como metáfora, mas presume-se que a realidade social e o palco teatral sejam coisas diferentes. Kärreman (2001, p. 95) enfatiza que a "[...] interação humana não é idêntica ao drama, mas sim algo que, do ponto de vista analítico, é construtivamente visto como se fosse dramático e teatral". Goffman (1959) desenvolveu sua abordagem como uma metáfora para analisar a mecânica das interações e performances humanas e não para interpretar seus significados. Nesse sentido, tem-se uma visão fraca das performances sociais (ALEXANDER; SMITH, 2004). Por outro lado, Burke (1969) não utiliza o drama como uma metáfora para ações humanas, mas sim como metonímia (CZARNIAWSKA-JOERGES, 1997). Assim sendo, o drama é visto como inerente à ação humana, como um componente central dos significados, da motivação e do que é o entendimento de ser humano. A vida social é analisada como um drama em termos literais (BROCK et al., 1985). A organização como um drama metonímico relaciona-se ao que Alexander e Smith (2004) denominam como uma visão forte das performances sociais, analisando a retórica e os rituais da vida organizacional como efetivamente são.

Na visão fraca da mudança como se fosse drama, cada peça teatral possui plateias diferentes e 0 ator precisa modificar sua performance, de acordo com a peça e a plateia (GOFFMAN, 1959). A performance é construída com o desenvolvimento de elementos físicos, verbais e mentais, de forma a oferecer a impressão correta aos indivíduos, o que o autor chama de gerenciamento da impressão. A análise das interações sociais, a partir da lógica do gerenciamento da impressão em Goffman (1959), requer o reconhecimento e a delimitação de regiões diferentes. De um lado, no frontstage (palco), a performance é entregue (por exemplo, como em um palco onde ocorre uma peça); e no backstage (bastidores), ocorre a performance por trás da encenação ao público. No palco, os atores mantêm os padrões 
e a gentileza, desempenhando seus papéis diante de todos. Por outro lado, nos bastidores, ocorrem ensaios, treinamento e funções ligadas à construção de ilusões.

Considerando a visão fraca da mudança como se fosse drama, o framework $5 \mathrm{M}$ é capaz de delinear aspectos práticos sobre como os gestores devem lidar com o desafio do gerenciamento da impressão, entrelaçando as performances de palco e bastidores, para realizar o gerenciamento para a mudança (BUCHANAN; BODDY, 1992). No palco, gestores apresentam a performance formal e pública (BURNS, 1961) exigida pela ethos legal e racional das organizações modernas (WEBER, 1997). Executam tarefas e projetam modelos para alcançar os objetivos da mudança, participando da retórica da racionalidade (MARCH; OLSEN, 1983). Por outro lado, também abordam o informal nos bastidores, arena caracterizada por March e Olsen (1983) como a retórica do realpolitik.

Comparando os 5M com a visão fraca de Goffman, manter-se atento ou agir conscientemente em relação à mudança requer ter atenção às lacunas entre intenção e realidade, bem como às barreiras à mudança, entendendo seu caráter complexo. 0 manter-se atento é similar à improvisação e ao desempenho criativo de músicos tocando jazz (KANTER, 2002; VERA; CROSSAN, 2004). Como os músicos de jazz, os gestores, em vez de aplicarem técnicas, descobrem metas e objetivos, criam e se engajam na prática, estando atentos ao inesperado. Sua performance, apesar de controlada, não é predeterminada (MANGHAN; PYE, 1991; WEICK, 1998).

A mobilização de pessoas, energias e recursos é, na visão fraca da mudança como se fosse drama, comparada à produção e direção de peças teatrais. Implica mobilizar escritores, produtores, diretores e atores, buscar fundos, canais de distribuição e outras questões inerentes à produção teatral, simbolizando diferentes questões e atores organizacionais (MANGHAM; OVERINGTON, 1983; 1987).

0 mapeamento assemelha-se às performances teatrais que ocorrem no palco. Refere-se aos roteiros e à própria encenação, que resultarão em uma apresentação de sucesso. Mapear a jornada não conduz à mudança, a não ser que as lideranças realizem a mudança na prática, influenciando pessoas. Essa condução refere-se ao gerenciamento da impressão, ao tirar e colocar máscaras, de forma a causar uma impressão significativa na plateia (WEICK, 1995). Essa atuação é necessária para fornecer à plateia uma impressão consistente com os objetivos desejados para a mudança (GOFFMAN, 1959).

Por fim, o mirar ou olhar pelo espelho, criando e fornecendo reflexões sobre o gerenciamento para a mudança, é semelhante aos ensaios e críticas das atuações teatrais. Esse olhar envolve organizar ensaios, monitorar respostas e reações de plateias, bem como revisar os roteiros e cenas. Ensaiar e rever o desempenho permite o monitoramento de respostas e reações à mudança em curso, proporcionando uma visão compartilhada do que está efetivamente acontecendo (CLARK; MANGHAM, 2004a; 2004b; OVERINGTON; MANGHAM, 1982).

partir da visão forte da mudança como drama, Burke (1969) argumenta que a vida em sociedade é um drama em termos literais (BROCK et al., 1985; GUSFIELD, 1989). Para Burke (1969), a vida social é inerentemente dramática, conflitiva, incerta, retórica e variável. Ele estudou as maneiras pelas quais os homens organizam suas experiências e as tornam compreensíveis para si mesmos e para os demais. 0 dramatismo "[...] nos convida 
a considerar os temas dos nossos motivos em uma perspectiva que, desenvolvida por meio da análise do drama, trata a linguagem e o pensamento, antes de tudo, como modos de agir" (BURKE, 1969, p. 22). O autor afirma que as razões pelas quais as pessoas agem, os motivos que dão a si mesmas e aos demais são baseados na maneira como elas entendem ou captam o que é relevante, possível e apropriado para dada situação.

$\mathrm{Na}$ visão forte da mudança como drama, o gerenciamento para a mudança é um encontro dramático e imprevisível, no qual motivos, intenções e explicações causais são sempre incertos, ambíguos e entrelaçados, em condições que não são dadas, mas sim representadas em interações sociais mais ou menos negociadas e significativas (WEICK, 2001). O gerenciamento para a mudança é entendido "[...] como interação social situada que ocorre em rituais de interação como narrativas representadas e envolve uma agência humana mais ou menos intencional e reflexiva" (BADHAM; MEAD; ANTONATOPOULOU, 2012, p. 197). A performance situacional complexa, segundo Denzin (1992), entrelaça a autointeração (em um diálogo interno) e a interação social (em um diálogo externo) dos participantes. Nesse sentido, gerenciamento de impressão ocorre dentro de contextos culturais integrados, que incluem as narrativas oferecidas, a trama elaborada e os motivos/ natureza identificados como apropriados e significativos (CZARNIAWSKA-JOERGES, 1997). Gerenciar performances estende-se, portanto, muito além das atuações de palco ordenadas por atores e plateias.

Comparando essa abordagem ao framework 5M, manter-se atento significa estar consciente da retórica e dos rituais dinâmicos, bem como estar sensível a características expressivas (EDGLEY, 2003) da performance humana (TURNER, 1985), monitorando de forma reflexiva as atuações que ocorrem durante a ação e a mudança (HARRE; SECORD, 1973). Como um veículo retórico, os $5 \mathrm{M}$ conduzem o líder - homo performans (TURNER, 1985) - a refletir sobre a sua própria performance e a da equipe, em vez de meramente aplicar técnicas racionais.

A mobilização refere-se ao caráter e ao uso de motivações ritualísticas e retóricas. Implica o exercício do poder para definir o que, quando, onde, quem, como e por que (BURKE, 1969) serão realizadas as práticas envolvidas na mudança, bem como a identificação com seus objetos e rituais simbólicos (ALEXANDER, 2004), compreendendo e capturando o vocabulário da motivação. Energizar os participantes e conectá-los uns com os outros aumenta a identificação com os objetos simbólicos e com os rituais (ALEXANDER; SMITH, 2004).

O mapeamento da jornada remete à preparação das dimensões retórica e ritualística dos rituais de transição - a separação inicial dos participantes da rotina diária; a orientação sobre a fase liminar ou o ponto de passagem para a mudança; e a reincorporação ao novo quadro estrutural e cultural (TURNER, 1982). Situações de mudança envolvem rituais e cerimônias que marcam seu início, meio e fim. O modelo de Lewin (1964) de descongelamento, movimento e recongelamento ajuda a capturar e endereçar a dinâmica desse ritual de transição (TURNER, 1982).

O desempenho retórico e ritual referente a usar máscaras tem como critérios a refusão e a autenticidade para transmitir o significado desejado da mudança, criando uma conexão emocional entre plateia, atores e texto, superando a fragmentação da sociedade moderna complexa e criando um fluxo de autenticidade, conforme proposto por Alexander 
(2004) e Alexander e Smith (2004). Dessa forma, usar o framework 5M permite ajudar os gestores a criarem o que Alexander (2004) caracteriza como o "desafio da refusão" na sociedade moderna, por meio de performances que ecoem em audiências diversas e fragmentadas.

Usar espelhos ou mirar indica a criação de espaços de aprendizagem, capturando a realidade para apoiar a reflexão, a adaptação e a melhoria da mudança em curso, superando as defesas cognitiva, emocional e política. Esse é o momento para trazer o público para o desempenho, dando-Ihe voz, a exemplo da imagem do teatro do oprimido de Boal (1979; 2005) ou de uma prática educativa de Freire (1987; 2000). A retórica alternância e espaço liminar destaca a ambiguidade ou desorientação que ocorre na fase intermediária, quando os participantes, na passagem entre seu modo anterior de estruturação, de identidade, de relacionamentos e a maneira nova e atual, estabelecem rituais de mudança (TURNER, 1982; TURNER, 1985).

Como a dramaturgia é tradicionalmente associada à visão de Goffman, ao entendimento de organizações como se fossem drama e tendo-se em vista que o que se busca aqui é combinar essa visão com a dramática de Burke - organizações como drama de fato -, optou-se por caracterizar as duas visões "fraca" e "forte" como uma abordagem geral aqui denominada "drama". Unir as duas visões significa o gerenciamento para mudança como performance social para atingir uma ressonância cultural (ALEXANDER; SMITH, 2004). Essa discussão traz aprofundamento e explicações adicionais ao trabalho de Badham, Cançado e Darief (2015, p. 10), sintetizados no Quadro 2, que delineia as diferenças entre as duas visões, como variantes da racionalidade densa dos $5 \mathrm{M}$.

Quadro 2 - Abordagem do drama: a visão fraca e forte no gerenciamento para mudança

\begin{tabular}{|c|c|c|}
\hline \multirow{2}{*}{$\begin{array}{l}\text { Racionalidade } \\
\text { densa - 5M }\end{array}$} & Visão fraca & Visão forte \\
\hline & Teatro & Ritual e retórica \\
\hline \multirow{3}{*}{ Manter-se atento } & Improvisando & Consciência ampla \\
\hline & - Estar ciente do inesperado & - Homo performance \\
\hline & $\begin{array}{l}\text { - Processo criativo e espontâneo como o } \\
\text { jazz }\end{array}$ & $\begin{array}{l}\text { - Capaz de pensar a performance de forma } \\
\text { reflexiva e de monitorar a ação e a mudança }\end{array}$ \\
\hline \multirow{4}{*}{ Mobilizar } & Produzindo peças & Engajamento \\
\hline & $\begin{array}{l}\text { - orquestrar e criar recursos para os } \\
\text { diferentes papéis, como em uma peça de } \\
\text { teatro - diretores, escritores, atores, críticos } \\
\text { e público }\end{array}$ & $\begin{array}{l}\text { - Motivação e engajamento por meio de } \\
\text { rituais - poder e práticas }\end{array}$ \\
\hline & & $\begin{array}{l}\text { - Criar identificação com objetos simbólicos } \\
\text { e rituais }\end{array}$ \\
\hline & & $\begin{array}{l}\text { - Compreender e influenciar os vocabulários } \\
\text { de motivo }\end{array}$ \\
\hline
\end{tabular}




\begin{tabular}{|c|c|c|}
\hline \multirow{2}{*}{$\begin{array}{l}\text { Racionalidade } \\
\text { densa - 5M }\end{array}$} & Visão fraca & Visão forte \\
\hline & Teatro & Ritual e retórica \\
\hline \multirow{3}{*}{ Mapear } & Encenando peças & Preparação da transição \\
\hline & - Dirigir e planejar, encenar a produção & $\begin{array}{l}\text { - Criação de retórica de práticas rituais para } \\
\text { apoiar as pessoas na passagem das fases } \\
\text { de separação, liminaridade e incorporação }\end{array}$ \\
\hline & $\begin{array}{l}\text { - Obter ressonância por meio do alinha- } \\
\text { mento dos atores, roteiros, encenação e } \\
\text { audiência }\end{array}$ & - criação de rituais de transição \\
\hline \multirow{4}{*}{ Usar máscaras } & Empregando cenografia & Encenação \\
\hline & - Palco e bastidores & $\begin{array}{l}\text { - Abordar barreiras devido à complexidade, } \\
\text { pluralidade e a fragmentação da sociedade } \\
\text { moderna }\end{array}$ \\
\hline & - Gerenciamento da impressão & - Refusão entre ator, roteiro e público \\
\hline & $\begin{array}{l}\text { - Improvisação e interação para garantir } \\
\text { performances ressonantes }\end{array}$ & \\
\hline \multirow{4}{*}{ Mirar } & Ensaiando e revisando & Olhar alternado \\
\hline & - Ensaios e treinamento & $\begin{array}{l}\text { - Alternar entre olhar o desempenho e olhar } \\
\text { a partir dele }\end{array}$ \\
\hline & $\begin{array}{l}\text { - Monitoramento das respostas e reações } \\
\text { dos públicos }\end{array}$ & $\begin{array}{l}\text { - Estabelecer suposições e perguntas que } \\
\text { permitam mudar a mentalidade }\end{array}$ \\
\hline & - Obter comentários e moldar, adaptar-se & \\
\hline
\end{tabular}

Fonte: Badham, Cançado e Darief (2015).

O gerenciamento para a mudança, portanto, é visto como ocorrendo em e por meio de uma série de encontros episódicos e interativamente narrados (GOFFMAN, 1959; HARRE; SECORD, 1973). Atuando no gerenciamento para a mudança, os gerentes, como atores, têm que influenciar os outros, inspirando-os a entrar, mover e sair, lidando com múltiplas e conflitantes expectativas, interpretações e motivos (EDGLEY, 2003). Eles também têm de lidar com os processos ritualizados (COLLINS, 1998; TURNER, 1982), com roteiros diferentes para cada cena, adotando várias encenações para atingir o público, comunicando e reforçando a jornada da mudança. É um jogo de gerenciamento de impressão que enfatiza a distância do papel, conflito e ambiguidade e o papel criativo dos atores/gestores (MANGHAM; OVERINGTON, 1987). A retórica e os rituais do gerenciamento da mudança são a do frontstage, racional, ordenada e planejada. A retórica e os rituais do gerenciamento para a mudança são a do backstage, da incerteza, das emoções e da desordem dos bastidores políticos.

\section{AVALIAÇÃO E APLICABILIDADE DO FRAMEWORK5M}

Em termos da aplicação, houve um esforço inicial (BADHAM; CANÇADO, 2014; BADHAM; CANÇADO; DARIEF, 2015) para analisar a natureza e os resultados do framework $5 \mathrm{M}$ no ensino do gerenciamento para a mudança, na disciplina Gestão da Mudança 
do curso de Master of Business Administration (MBA) da Macquarie Graduate School of Management, Australia. O curso utiliza o framework 5M como um veículo retórico, prático e reflexivo, adotando imagens, estórias, filmes e simulações provocativos e emotivos. Essa metodologia tem respaldo principalmente na pedagogia de Freire $(1987 ; 2000)$ e no teatro do oprimido de Boal $(1979 ;$ 2005). Os alunos, que são predominantemente gestores seniores que trabalham em grandes empresas de serviço australianas, são avaliados pelo sucesso na criação de um diário de aprendizagem (HAYS, 2004) e pela condução de um projeto de mudança que envolva ação e reflexão no mundo real, em seu local de trabalho. Em mais de 10 anos foram elaborados mais de 1.000 projetos de intervenção em empresas, o que permitiu que a proposição do framework $5 \mathrm{M}$ fosse desenvolvida e refinada (BADHAM; CANÇADO, 2014).

Esses diários de aprendizagem forneceram uma base de dados qualitativa que permitiu explorar o efeito do framework $5 \mathrm{M}$ e, em particular, o grau de sucesso na alteração da mentalidade dos alunos de uma visão limitada para a densa, bem como a incorporação da visão fraca e forte sobre a maneira como eles atuam e refletem sobre as mudanças organizacionais.

Conforme apresentado em Badham e Cançado (2014) e Badham, Mead e Antonacopoulou (2015), foram utilizados dados secundários, focando os resultados da tese de doutorado de Darief (2011). Visando analisar como alunos de cursos do MBA experimentaram e lidaram com as proposições e metodologias provocativas do curso, foram analisados 47 diários de aprendizagem elaborados como trabalho final do MBA. A tese baseou-se nos pressupostos de Brecht sobre os efeitos de Verfremdung, que se referem a "[...] interromper a visão e o pensamento habituais, criando um estado de incompreensão temporária e levando a uma visão crítica" (DARIEF, 2011). Parte dos resultados dessa tese foi discutida (BADHAM; CANÇADO, 2014; BADHAM; MEAD; ANTONACOPOULOU, 2015), tendo o framework $5 \mathrm{M}$ como referência. Os resultados do estudo revelaram que a resposta geral ao curso foi positiva - 70\% declararam que o curso foi "bom" e $30 \%$ "excelente" - e permitiram identificar três tipos de resposta dos alunos quanto ao curso, caracterizando um grupo acrítico, um seletivo e outro reflexivo.

Cada um desses grupos expressou algum grau de choque e crítica ao formato flexível e aberto do curso e à falta de foco no ensino de métodos e ferramentas práticas para gerenciar a mudança. De certa forma, o grupo acrítico mostrou-se mais preparado para o tipo 'diferente' de aula, uma vez que alguns alunos já tinham conversado com colegas e realizado a leitura prévia do material da disciplina. Expressaram alguma apreciação pelo curso que, na percepção deles, reafirmou aquilo que já sabiam sobre mudança, ao menos implicitamente. Ressaltaram que o curso ofereceu algumas 'ferramentas' adicionais, especialmente a do mapeamento, que utilizou a metodologia de simulação pelo computador, além da analogia do iceberg organizacional. Esses fatores aumentaram a autoconfiança desses alunos em suas habilidades para gerenciar a mudança.

O grupo seletivo mostrou-se mais chocado pelo formato do curso, tendo também ressaltado o valor do mapeamento. Apesar de os alunos desse grupo terem mostrado sinais de que aplicaram os conceitos do curso nas suas experiências diárias em suas respectivas empresas, eles não se mostraram profundamente engajados com o conteúdo. Observou-se, 
ainda, que a sua confiança na gestão da mudança, de modo geral, foi levemente diminuída em vez de aumentar.

O terceiro grupo, o reflexivo, que abarcou aproximadamente metade dos estudantes, chocou-se e foi crítico com o formato do curso. Esses alunos mostraram-se engajados com o material e obtiveram experiências de aprendizado mais profundas. Elogiaram algumas das ferramentas ensinadas e, especialmente, reconheceram, em grande medida, as dimensões pessoal, interpessoal e organizacional da mudança, bem como a natureza incerta e complexa dos processos e performances. Um dos alunos/gestor opinou que "[...] o conhecimento sobre a mudança me parece agora como sendo a arte de um sábio" (BADHAM; CANÇADO, 2014).

Existem limitações na utilização desses dados, que envolveram relatórios preparados poucas semanas depois da conclusão do curso e foram analisados inicialmente com objetivo diferente do deste estudo. Para futuras pesquisas, os questionamentos e processo de elaboração dos diários de aprendizagem podem ser acompanhados por um pesquisador que assista às reuniões dos pequenos grupos de discussão. Podem também ser realizadas entrevistas individuais complementares com alunos-gestores pelo pesquisador. 0 foco deve ser na operacionalização e na avaliação do grau em que os alunos deslocam da visão limitada para a densa, extraindo-se informações também tanto da visão fraca quanto forte da abordagem da mudança como drama.

A caracterização das respostas dos diferentes grupos pode ser aperfeiçoada por meio de uma análise rigorosa de fatores individuais, organizacionais e intelectuais que influenciam as reações particulares dos alunos. Pode-se ainda complementar as informações utilizando-se testes e diagnósticos de liderança, assim como os dados de registro dos alunos no curso, para apurar informações acerca de características pessoais, estilos e posição organizacional dos participantes do curso. Sugere-se, ainda, a aplicação do framework $5 \mathrm{M}$ em situação real de empresas que estejam vivenciando ou vivenciaram processos de mudança, de maneira a analisar o efetivo impacto retórico do gerenciamento para a mudança.

Qualquer avaliação desse tipo é hipotética por natureza, pois inevitavelmente existirão problemas para se separar o efeito do conteúdo do efeito da Pedagogia, do impacto de diferentes aspectos do curso, da influência do professor, e assim por diante. No entanto, dada a falta de frameworks já estabelecidos que preencham as funções retóricas pretendidas pelo 5M, bem como dada a ausência de investigação empírica de seus efeitos reais ou potenciais, este estudo torna-se valioso, não só para avaliar os seus efeitos, mas também para fornecer sugestão para posteriores refinamentos teórico-pedagógicos.

\section{CONSIDERAÇÕES FINAIS}

Existiria, então, diferença entre o que é aqui denominado de gerenciamento da mudança e gerenciamento para a mudança? Seria a mudança um exercício racional, planejado, regulado e controlado ou um jogo emotivo e político, envolvendo consciência ampliada e improvisação? Ou seria um simples jogo de palavras? Em verdade, trata-se sim de um jogo de palavras, mas que é significativo e importante. 0 framework $5 \mathrm{M}$ foi proposto como um veículo retórico, com o intuito de alterar o discurso prevalecente de um gerenciamento 
racionalista da mudança para uma visão mais densa e fundamentada no drama, do gerenciamento para a mudança.

A abordagem clássica para gerenciar a mudança é a racional que, em sua visão limitada, assume a busca por metas mais ou menos claras e por meios eficientes e motivação unitária-racional para alcançá-las - "the best way". É baseada em uma visão idealista, rígida, não crítica, universalista da moderna racionalidade, caracterizando, portanto, o gerenciamento da mudança. Essa visão contrasta-se fortemente com a visão densa da mudança que assume a existência e enfatiza a necessidade de se adaptar a objetivos plurais, conflitantes e ambíguos, bem como meios incertos e difusos para atingi-los. Essa abordagem apresenta um argumento mais multidimensional e situacional, simbolizando uma racionalidade "razoável", o que caracteriza o gerenciamento para a mudança. Recebeu reconhecimento crescente nas últimas décadas, sob o rótulo das abordagens processual, sensemaking e da visão baseada na prática. É uma abordagem que desafia retoricamente a tradicional-limitada, sendo capaz de trazer insights mais pragmáticos, por meio do framework 5M, e estabelecer uma ponte reflexiva para a abordagem da mudança como drama.

Para explicar o drama e as performances envolvidas na mudança organizacional, a visão fraca usa a metáfora de organizações como se fossem drama. Introduz a linguagem e o ethos da improvisação, da produção/direção peças, da escrita de roteiros, execução de performances e ensaios/revisão de performances. O gerenciamento da impressão captura a superfície de um mundo inerentemente estruturado, dramático e performativo. Já a visão forte considera a vida organizacional como um drama de fato, estabelecido por uma performance social, como uma forma de ação de indivíduos e grupos cuja motivações são construídas retoricamente e expressas por meio de rituais. O gerenciamento para a mudança envolve uma consciência reflexiva sobre a maneira e o grau em que a mudança, seja intencional ou não, está incorporada no mundo e os eventos episódicos dramáticos que o compõem.

Combinando essas duas visões - visão fraca da mudança como se fosse drama de Goffman e visão forte da mudança como drama de fato de Burke - por meio do framework $5 \mathrm{M}$, propõe-se a abordagem do drama para o estudo do gerenciamento para a mudança. Unir as duas visões, comparando-as com a visão tradicional, traz o gerenciamento para a mudança como performance social, visando atingir a ressonância cultural. Dessa forma, o framework 5M, concebido como um veículo retórico, possibilita essa metalinguagem, com o intuito de alterar o discurso da gestão da mudança. Propõe assim o deslocamento da prática de um gerenciamento racionalista da mudança para uma percepção mais densa e fundamentada no drama, do gerenciamento para a mudança.

Sendo assim, essa proposição começa, possivelmente, a abordar uma lacuna nas abordagens acadêmicas sobre o gerenciamento da mudança, por meio do desenvolvimento de um quadro de referência aplicável a pesquisas, bem como considerado relevante e útil para a mudança na prática. O esforço para avaliar esta proposição, ainda que de forma sugestiva, indica impacto significativo e o papel retórico educacional pretendido. 0 presente estudo é útil por fornecer uma base para o desenvolvimento e aperfeiçoamento teórico-pedagógico posteriores, sugerindo-se investigações empíricas em empresas, sobre efeitos reais e potenciais do framework $5 \mathrm{M}$. 


\section{REFERÊNCIAS}

ALEXANDER, J. The politics of performance. New York: Oxford University Press, 2012.

ALEXANDER, J.C. Cultural pragmatics: social performance between ritual and strategy. Sociological Theory, v. 22, p. 527-573, 2004.

ALEXANDER, J.C.; SMITH, P. The strong program in cultural sociology. In: ALEXANDER, J.C. (ed.). The meanings of social life: a cultural sociology. New York: Oxford University Press, 2004.

ARGYRIS, C. Organizational traps: leadership, culture, organizational design. New York: Oxford University Press, 2010.

Overcoming organizational defenses: facilitating organizational learning. New York: Prentice Hall, 1990.

ARIELY, D. Predictably irrational: the hidden forces that shape our destiny. New York: HarperCollins, 2008.

BADHAM, R. Inspiring Change. (MGSM866 - Managing change 2014, Term 1). Sydney: Macquarie University, Macquarie Graduate School of Management, 2014.

Short change: An introduction to managing change. Ukraine: Business Perspectives Publishing Company, 2013.

. Mind(ing) the Gap: The irony of practice and the practice of irony. In: ORGANISATION STUDIES SUMMER WORKSHOP, 2., 2006, Mykonos, Greece. Anais [...]. Mykonos, Greece, 2006.

BADHAM, R.; CANÇADO, V.L. The mindful mobilising of maps, masks and mirrors: shifting the rhetoric of organisational change. In: Encontro ENANPAD, 38., 2014, Rio de Janeiro. Proceedings [...]. Rio de Janeiro: ANPAD, 2014. p. 1-16.

BADHAM, R.; CANÇADO, V.L.; DARIEF, T. An introduction of the 5M framework: reframing change management education. BAR. Brazilian Administration Review, v. 12, n. 1, p. 22$38,2015$.

BADHAM, R.; MEAD, A.; ANTONACOPOULOU, E. Performing change: a dramaturgical approach to the practice of managing change. In: BOJE, D.M.; BURNES, B.; HASSARD, J. (eds). The routledge companion to organizational change. London/New York: Routledge, 2012. p.187-205

BECKHARD, R. Organization development: strategies and models. Boston/MA: Addison-Wesley Publishing, 1969.

BEER, S.; NOHRIA, N. (eds.). Breaking the code of change: resolving the tension between theory E and O of change. Boston: Harvard Business Press, 2000.

BENNIS, W.G. Organization development: its nature, origins and prospects. Boston/MA: Addison-Wesley Publishing, 1969.

BOAL, A. Teatro do oprimido e outras poéticas políticas. ed. rev. Rio de Janeiro: Civilização Brasileira, 2005. 
BOAL, A. Theatre of the oppressed. 2. ed., London: Pluto Press, 1979.

BLOOR, D. Knowledge and Social Imagery. London: Routledge, 1976.

BRIDGES, W.; BRIDGES, S. Managing transitions. Making the most of change. Cambridge/ Mass: Da Capo Lifelong Books, 2009.

BROCK, B. et al. Dramatism as ontology or epistemology: A Symposium. Communication Quarterly, v. 33, v. 1, p. 17-33, 1985.

BROWN, S.L.; EISENHARDT, K.M. Competing on the edge: strategy as structured chaos. Boston: Harvard Business Press, 1998.

BRUCH, H.; VOGEL, B. Fully charged: How great leaders boost their organization's energy and ignite high performance. Boston: Harvard Business Review Press, 2011.

BUCHANAN, D.; BADHAM, R. Power, politics and organizational change: winning the turf game. London: Sage, 2008.

BUCHANAN, D.; BODDY, D. The expertise of the change agent: public performance and backstage activity. New York: Prentice Hall, 1992.

BURKE, K. A grammar of motives. Berkeley: University of California Press, 1969.

BURNS, T. Micropolitics: mechanisms of institutional change. Administrative Science Quarterly, v. 55, p. 257-281, 1961.

CLARK, T.; MANGHAM, I. From dramaturgy to theatre as technology: the case of corporate theatre. Journal of Management, v. 41, n. 1, p. 37-51, 2004a.

. Stripping the undercoat: review and reflections on a piece of organization theatre.

Organization Studies, v. 25, n. 5, p. 841-851, 2004b.

COLLINS, D. Organizational change: sociological perspectives. London: Routledge, 1998.

COVEY, S.R. The seven habits of highly effective people. New York: Rosetta Books, 2009.

The 8th habit: from effectiveness to greatness. New York: Free Press, 2005.

CZARNIAWSKA-JOERGES, B. Narrating the organization: dramas of institutional identity. Chicago: University of Chicago Press, 1997.

DARIEF, T. Verfremdung in Management Education: Initiating Critical Reflection. Thesis (Doctor of Philosophy). Macquarie University/MGSM, Sydney, Australia, 2011.

DENZI, N. K. Symbolic interactionism and cultural studies: the politics of interpretation. Oxford: Blackwell, 1992.

EDGLEY, C. The dramaturgical genre. In: REGYNOLDS, L.T.; HERMAN-SKINNEY, N.J. (eds.). Handbook of symbolic interactionism. New York: Rowman \& Littlefield, 2003.

FREIRE, P. Pedagogy of the oppressed. New York: Bloomsbury, 2000.

Pedagogia do oprimido. 17. ed., Rio de Janeiro: Paz e Terra, 1987.

FUDA, P. Transforming leadership: How ordinary managers become extraordinary leaders. Boston: New Harvest, 2013.

GALLOS, J. Organization development. San Francisco: Jossey-Bass, 2006. 
GEERTZ, C. The interpretation of cultures: selected essays. New York: Basic Books, 1983. GOFFMAN, E. The presentation of self in everyday life. New York: Anchor Books, 1959.

GOLEMAN, D. Emotional intelligence. New York: Bantam Books, 1995.

GRINT, K. The arts of leadership. New York: Oxford University Press, 2001.

GUSFIELD, J.R. Introduction. In: BURKE, K. On symbols and society. Chicago: The University of Chicago Press, 1989.

HARRE, R.; SECORD, P.F. The explanation of social behaviour. Totowa, NJ: Littlefield Adams, 1973.

HAYS, J. Reflection, insight, and empathy: uncommon outcomes in management education. Paper presented at the 18th annual conference of the Australian and New Zealand Academy of Management, Dunedin, NZ, 8-11 December, 2004.

HEATH, C.; HEATH, D. Switch: how to change things when change is hard. New York: Broadway Books, 2010.

HUCZYNSKI, A. Influencing within organizations. London: Routledge, 2004.

ISERN, J.; MEANEY, M.C.; WILSON, S. Corporate transformation under pressure. New York: McKinsey \& Company, 2009. Disponível em: http://www.mckinsey.com/insights/organization/corporate_transformation_under_pressure. Acesso em: julho de 2017.

JABRI, M. Managing organizational change: process, construction and dialogue. London: Palgrave/Macmillan, 2012.

KANTER, R.M. Strategy As Improvisational Theater. MIT Sloan Management Review, v. 43, n. 2, p. 76-81, 2002.

The change masters. London: Routledge, 1983.

KÄRREMAN, D. The scripted organization: dramaturgy from Burke to Baudrillard. In: WESTWOOD, R.; LINSTEAD, S. (eds.). The language of organization. London: Sage, 2001, p. 90-112.

KEGAN, R.; LAYEY, L. Immunity to change: How to overcome it and unlock the potential in yourself and your organization. Boston: Harvard Business Review Press, 2009.

KELLER, S.; AIKEN, C. The inconvenient truth about change management: Why it isn't working and what to do about it. McKinsey Quarterly, April. New York: McKinsey \& Company, 2009. Disponível em: https://www.aascu.org/corporatepartnership/McKinseyReport2. pdf. Acesso em: julho de 2017.

KOTTER, J. Leading change. Boston: Harvard Business School Press, 2012.

LANGER, E. Mindfulness. Cambridge: Da Capo Press, 1990.

LATOUR, B.; WOOLGAR, S. Laboratory life: the construction of scientific facts. Princeton, NJ: Princeton University Press, 1986.

LAWRENCE, P.; LORSCH, J. Organization and environment. Boston/MA: Harvard, 1967.

LEWIN, K. Field theory in social science: selected theoretical papers. New York: Harper \& Row, 1964. 
MANGHAM, I.L.; PYE, A. The doing of managing. Oxford/UK: Blackwell, 1991.

MANGHAM, I.L.; OVERINGTON, M.A. Organization as theatre: a social psychology of dramatic appearances. Chichester: John Wiley \& Sons, 1987.

. Dramatism and the theatrical metaphor. In: MORGAN, G. (ed.). Beyond the method: strategies for social research. Beverly Hills: Sage, 1983.

MARCH, J.G. A primer on decision making. New York: Free Press, 1994.

. Footnotes to organizational change. Administrative Science Quarterly, v. 26, n. 4, p. 563-577, 1981.

MARCH, J.G.; OLSEN, J.P. Organizing political life: what administrative reorganization tells us about government. American Political Science Review, v. 77, n. 2, p. 281-96, 1983.

NONAKA, I.; TAKEUCHI, H. The knowledge-creating company. New York: Oxford University Press, 1995.

OVERINGTON, M.A.; MANGHAM, I.L. The theatrical perspective. Organizational Analysis Symbolic Interaction, v. 5, n. 2, p. 173-185, 1982.

PALMER, I.; DUNFORD, R.; AKIN, G. Managing organizational change. New York: McGraw Hill, 2008.

PFEFFER, J. Managing with power. Boston: Harvard Business School Press, 1994.

RYLE, G. The thinking of thoughts: What is 'Le Penseur' doing? University Lectures, The University of Saskatchewan, n. 18, 1968. Acesso em: julho de 2017.

The concept of mind. Harmondsworth: Penguin Books, 2000.

SCHEIN, E. Process consultation: Its role in organization development. Boston/MA: Addison-Wesley Publishing, 1969.

SCHÖN, D.A. The reflective practitioner: how professionals think in action. New York: Basic Books, 1983.

SENGE, P. et al. The dance of change: the challenges to sustaining momentum in learning organizations. New York: Crown Business, 1999.

SENSE, A. Cultivating the learning within projects. London: Palgrave/Macmillan, 2008.

STACEY, R. Tools and techniques of leadership and management: Meeting the Challenge of Complexity. London: Routledge, 2012.

TURNER, E. (ed.). On the edge of the bush: Anthropology as experience. Tucson: University of Arizona Press, 1985.

TURNER, V. From ritual to theatre: The human seriousness of play. New York: PAJ Publications, 1982.

VERA, D.; CROSSAN, M. Theatrical improvisation: Lessons for organizations. Organization Studies, v. 25, n. 5, p. 727-49, 2004.

WALTON, R.E. Interpersonal peacemaking: Confrontations and third party consultation. Boston/MA: Addison-Wesley Publishing, 1969. 
WEBER, M. The theory of social and economic organization. New York: Free Press, 1997. WEICK, K. Making sense of the organization. Oxford: Blackwell, 2001. . Introductory essay: improvisation as a mindset for organizational analysis. Organization Science, v. 9, n. 5, Special Issue, p. 543-555, 1998.

Sensemaking in organizations. Thousand Oaks, CA: Sage, 1995.

WEICK, K.; QUINN, R. Organizational development and change. Annual Review of Psychology, v. 50, p. 361-86, 1999.

WEICK, K.; SUTCLIFFE, K. Managing the unexpected: Assuring high performance in an age of complexity. San Francisco, CA: Jossey-Bass, 2001.

WEISBORD, M. Productive workplaces: Dignity, meaning, and community in the 21 st century. Hoboken: Pfeiffer, 2011.

ZERUBAVEL, E. The elephant in the room: Silence and denial in everyday life. New York: Oxford University Press, 2006.

Data de Submissão: 17/01/2017.

Data de Aprovação: 18/04/2018. 